\title{
Effect of Cooperative Learning Strategy on the Creative Thinking Skills of Secondary School Students of Kozhikode District
}

\author{
Elizabeth B.John ${ }^{1}$, Dr. Meera, K.P ${ }^{2}$ \\ ${ }^{I}$ (Senior Research Fellow, Department of Education, University of Calicut, India) \\ ${ }^{2}$ (Associate Professor, Department of Education, University of Calicut, India)
}

\begin{abstract}
Education is the structuring of a situation in ways that help students change through learning and learning is a change within the student that is brought about by the instructional programme of a school. The importance of school as a model of the society in helping them become responsible citizens cannot be overlooked. The present study was conducted to investigate the indirect effect of Cooperative Learning Strategy in Mathematics instruction on the creative thinking skills of standard VIII pupils.Quasi experimental design was employed in the study. From the same school, one standard VIII class was randomly selected as the experimental group and another as the control group for the experimentation. The experimental group was taught Mathematics using Cooperative Learning Strategy and the control group was taught through the Activity Oriented Method of teaching. Data was collected and analyzed using appropriate statistical techniques. The result revealed that Cooperative Learning Strategy is more effective than the Activity Oriented Method in fostering the Creative Thinking Skills of the secondary school students.
\end{abstract}

Keywords: Cooperative Learning Strategy, Creative Thinking Skills, Secondary School Students

\section{Introduction}

The phenomena of globalization which transformed the world trade, communication and economic relations in the latter part of the twentieth century has also made profound effect on education at the start of the twenty-first century. This has been evidenced by the increased global competition for the best and brightest students. In this scientifically and technologically advanced period, an average individual-with average skills and capacities-need to strive hard to make his/her life. Schools should prepare students for careers and life (Goodlad, 1984) (1).We have to see whether they can understand things or not, whether they can translate it into real life situations or not.

In these days, the thinking process of our students seems so much distorted that their very actions reflect the extremely unhealthy part of their personality. Though unhealthy academic competitiveness have been swiped off from our schools owing to the introduction of the new system of education, many incidents show that student thoughts are leading towards negative processes; they're not using their brains for creative thinking or to retain something permanently. Following a nationwide move proposed in the form of NCF-2005 (2), public attention was focused on what should be taught to children and how. NCF stood for that education which would give our children some taste of understanding, following which they would be able to learn and create their own versions of knowledge as they go out to meet the world of bits, images and transactions of life, which would make the present of the children wholesome, creative and enjoyable.

\section{Need and Significance}

Teaching relevant and important Mathematics embedded in the child's experience can cover a broad spectrum of aims. Mathematics education is essentially a practical discipline where the underlying goal is always to promote better learning of Mathematics by students. Of course, there are many subtleties of what Mathematics should be learned and why, in what interest is that students learn, how achievement is measured etc. But the discipline of Mathematics education is underpinned by a faith that a good education in mathematics benefits both the individual and the society.

The three goal structures-cooperative, competitive and individualistic-needs to be used depending upon their specific instructional objectives. The inappropriate use of competition and the isolate nature of individualistic education keep them apart. The most under-utilized and the most valuable goal structure is cooperation. Cooperative Learning is any learning activity in which students of adverse backgrounds work together in group toward a specific goal. There is broad agreement that Cooperative Learning methods should be promoted in teaching Mathematics and Science. 


\section{Statement of the problem}

The study was intended to find out the effect of Cooperative Learning Strategy on the Creative Thinking Skills of Secondary School Students of Kozhikode District .The study is thereby entitled as "Effect of Cooperative Learning Strategy on Creative Thinking Skills of Secondary School students of Kozhikode District".

\section{Objectives}

To study the effect of Cooperative Learning Strategy over Activity Oriented method of teaching on Creative Thinking Skills.

\section{Hypotheses}

1. Mean pre-test scores of Creative Thinking Skills will not differ significantly between the experimental and control groups.

2. Significant difference will exist in the mean post-test scores of Creative Thinking Skills between the experimental and control groups, with advantage to the experimental group.

3. Mean gain scores in the test of Creative Thinking Skills of the experimental and control groups will differ significantly, with advantage to the experimental group.

4. Mean gain scores in the test of Creative Thinking Skills of the experimental and control groups will differ significantly, with advantage to the experimental group when the effect of pre-test score is controlled.

\section{Methodology}

The study employs pre test- post test non-equivalent group design (quasi experimental design) of experimentation. The instructional procedure is treated as the independent variable and creative thinking skill as the dependent variable. Pre-test scores alone is opted as the control variable.

\section{Sample}

Being an experimental study, the investigator randomly selected two intact standard VIII classes of the same school from Kozhikode District as the representative of the secondary schools of Kozhikode.

Tools

The investigator developed and used the following tools in the study:

1. Test on Creative Thinking Skills (John \& Meera, 2009).

2. Lesson transcripts based on Cooperative Learning Strategy and the existing method of teaching mathematics on the same content (John \& Meera, 2009).

Statistical Techniques Employed

1. Mean Difference Analysis

2. ANCOVA

\section{Analysis and Interpretations}

Following the preliminary analysis for normality assumptions, the data were subjected to parametric statistical analysis. The results obtained are provided in the sections below.

\section{Preliminary Analysis}

Basic descriptive statistics calculated for the pre test scores on the dependent variable for the experimental group and the control group is provided in TABLE 1.

Table .1 .Descriptive Statistics for the Pre-Test scores on Creative Thinking Skills of the Experimental

\begin{tabular}{lllllll}
\multicolumn{7}{c}{ Group and the Control Group } \\
\hline Group & Mean & Median & Mode & Standard Deviation & Skewness & Kurtosis \\
\hline Control Group & 68.73 & 68.5 & 44 & 27.31 & 0.5981 & 0.1299 \\
Experimental Group & 66.68 & 68 & 50 & 28.8 & 0.5895 & -0.081 \\
\hline
\end{tabular}

The basic descriptive statistics for the post-test scores on the dependent variable for the experimental group and that for the control group is provided in TABLE 2. 
Table .2 Descriptive Statistics for the Post-Test scores on Creative Thinking Skills of the Experimental

\begin{tabular}{lllllll}
\multicolumn{7}{c}{ Group and the Control Group } \\
\hline Group & Mean & Median & Mode & Standard Deviation & Skewness & Kurtosis \\
\hline Control Group & 73.57 & 67 & 47 & 33.22 & 0.963 & 0.774 \\
Experimental Group & 135 & 141 & 100 & 44.97 & -0.065 & -0.426 \\
\hline
\end{tabular}

The basic descriptive statistics for the gain scores on the dependent variable for the experimental group and that for the control group is provided in TABLE 3.

Table. 3 Descriptive Statistics for the Gain scores on Creative Thinking Skills of the Experimental Group and the Control Group

\begin{tabular}{lllllll}
\hline Group & Mean & Median & Mode & Standard Deviation & Skewness & Kurtosis \\
\hline Control Group & 4.84 & 2.5 & 1.5 & 12.11 & 3.544 & 12.88 \\
Experimental Group & 68.33 & 58.5 & 103 & 40.33 & 0.701 & 0.084 \\
\hline
\end{tabular}

From table 1 and table 2 we can see that the distribution of pretest scores post test scores on the dependent variable for the experimental group and the control group are found to be nearly normal as they have nearly equal mean, median and mode; have not much variation from mesokurtic curve and are not badly skewed. The near normal distribution obtained permits for parametric testing of the data. .From table 3 we can see that the distribution of gain scores on the dependent variable for the control group is positively skewed and platykurtic. The normal P-P plots however revealed that there are only slight deviations of observed cumulative probability from the diagonals. Tchebychef's Law of Large numbers that all distributions tend to Normal as $\mathrm{N}$ (sample size) becomes large and the not so serious deviations from normality of the data permits for parametric tests to be conducted on the data.

\section{Investigation of Group Differences}

Comparison of mean scores was carried out to test whether significant difference exist between mean pre-test scores of the experimental group and the control group in the dependent variable. Two tailed test of significance of difference between means was used for comparison and the results are given in TABLE 4.

Table .4 Data and Results of the Two Tailed Test of Significance of Difference between the Mean Pre-Test scores, and One Tailed Test of Significance of Difference between the Mean Post-Test scores and the Mean Gain scores on Creative Thinking Skills between the experimental group and the control group

\begin{tabular}{|c|c|c|c|c|c|c|}
\hline $\begin{array}{l}\text { Scores } \\
\text { Compared }\end{array}$ & Groups Compared & $\mathbf{N}$ & Mean & $\begin{array}{l}\text { Standard } \\
\text { Deviation }\end{array}$ & t-value & Level of significance \\
\hline \multirow[t]{2}{*}{ Pre-Test scores } & Experimental & 55 & 66.68 & 28.79 & \multirow{2}{*}{-0.384} & \multirow{2}{*}{ N.S } \\
\hline & Control & 55 & 68.74 & 27.3 & & \\
\hline \multirow[t]{2}{*}{ Post-Test scores } & Experimental & 55 & 135.01 & 44.97 & \multirow{2}{*}{8.149} & \multirow{2}{*}{0.01} \\
\hline & Control & 55 & 73.57 & 33.22 & & \\
\hline \multirow[t]{2}{*}{ Gain Scores } & Experimental & 55 & 68.33 & 40.33 & \multirow{2}{*}{11.18} & \multirow{2}{*}{0.01} \\
\hline & Control & 55 & 4.84 & 12.11 & & \\
\hline
\end{tabular}

The two tailed t-test performed to estimate the significance of difference between pre-test means of the two groups in Creative Thinking Skills shows that the differences are not significant enough. The two groups' pre-test means in Creative Thinking Skills is comparable. Any difference in pre-test means in Creative Thinking Skills scores of the two groups is not significant enough and can be attributed to chance. Thereby the two groups can be equated in terms of Creative Thinking Skills.

Results of one-tailed t-test performed to estimate the significance of difference between mean post-test scores of the experimental group and the control group, with advantage to any group, showed that there was a significant difference between the post-test means of the two groups(experimental and control) in Creative Thinking Skills.

Results of one-tailed t-test performed to estimate the significance of difference between mean gain scores of the experimental group and the control group in Creative Thinking Skills shows that the mean gain scores on Creative Thinking Skills of the experimental group and the control group differ significantly, with advantage to the experimental group.

This reveals that after the intervention, the two groups differ significantly in their mean scores in posttests of Creative Thinking Skills. The two groups' pre-test means in Creative Thinking Skills was initially comparable. After intervention, we can see that the mean scores in Creative Thinking Skills of the experimental group and the control group significantly differs, with advantage to the experimental group. Also, one-tailed ttest performed to estimate the significance of difference between mean gain scores of the experimental group 
and the control group, with advantage to any group revealed that there was a significant difference between the gain score means of the two groups(experimental and control) in Creative Thinking Skills; with advantage to the experimental group.

Though the gain score analysis yielded results more clear that the post-test analysis, investigator intended to nullify the effects of pre-test differences in the gain score analysis, if any. Selection of non-equated intact classes as the groups compared and the quasi-experimental design of the study worked as prompts to carry out Analysis of Covariance (ANCOVA) controlling for the pre-test effects on gain scores. Since the gain scores satisfied the assumptions of ANCOVA, this statistical technique was employed to the data. The results are given in TABLE 5.

Table. 5 Summary of single factor ANCOVA on gain scores in Creative Thinking Skills of students in Experimental group and Control group

\begin{tabular}{|c|c|c|c|c|c|c|c|}
\hline Variable & & $\begin{array}{ll}\text { Source } & \text { of } \\
\text { Variation } & \end{array}$ & $\mathbf{S S}_{\mathbf{X}}$ & df & MS & $\mathbf{F}$ & Level of significance \\
\hline $\begin{array}{l}\text { Creative } \\
\text { Skills }\end{array}$ & Thinking & $\begin{array}{l}\text { Between groups } \\
\text { Within groups } \\
\text { Total }\end{array}$ & $\begin{array}{l}110198.6 \\
95328.3 \\
353813\end{array}$ & $\begin{array}{l}1 \\
107 \\
110\end{array}$ & $\begin{array}{l}110198.6 \\
890.919\end{array}$ & 123.69 & 0.01 \\
\hline
\end{tabular}

From TABLE 4 it is evident that there is a significant difference between the mean gain scores of the experimental group and the control group on Creative Thinking Skills, after controlling for the pre-test scores. The tabled F-Value F $(1,107)$ is 3.94 at 0.05 level and 6.90 at 0.01 level. The F-value obtained for mean gain score differences in Creative Thinking Skills between the experimental group and the control group, after controlling for their pre-test scores in Creative Thinking Skills is 123.69 which is significant at 0.01 level.

\section{Major Findings}

- The experimental and the control groups do not show any significant difference in their pre-test scores of Creative Thinking Skills. The two groups are equal in their initial status.

- The experimental group taught through Cooperative Learning Strategy scored significantly more on the post-test of Creative Thinking Skills when compared to the control group.

- The experimental group taught through Cooperative Learning Strategy had significantly higher gain scores on Creative Thinking Skills when compared to the control group.

- In terms of gain scores on Creative Thinking Skills, students taught through Cooperative Learning Strategy is superior to students taught through Activity Oriented method of teaching, after controlling for their pre-test scores on Creative Thinking Skills.

\section{Educational Implications}

This study has demonstrated the advantages of Cooperative Learning Strategy in attaining creative thinking skills in students in a regular Mathematics class. Creative outputs of an individual being the essence of one's true self is always sought after. Cooperative Learning Strategy can help the learners to be prepared to face the world of reality at large, and to understand and accept their potentials and limitations in the right proportion to give the world their best. Moreover, group techniques such as Co-operative Learning will be helpful if applied systematically. Cooperation is a valuable commodity as it promotes goodwill toward men and women and is a gift that is always appropriate. Many studies show that when learners explain their meaning-making to each other, their learning is richer and deeper. The act of having to make sense to a peer challenges someone to clarify and communicate in such a way that their own understanding is enhanced. In such a classroom, therefore, a building block is the use of pairs who are involved in exchanging and co-creating explanations.

In the light of the findings of the present study, investigator suggests the need to practice Cooperative Learning Strategy so as to remain connected with his/her peers and at the same time use one another's potential for the upliftment of their peers and for that of their society and human kind at large. It is expected that the findings of the study will be helpful for the curriculum planners to include suitable versions of the content regarding the same and for the teachers to teach effectively with a sense of purpose and broader aims in mind.

\section{Conclusion}

From the second, third and fourth hypotheses, we could substantiate the superiority of Cooperative Learning Strategy over Activity Oriented method of teaching on the Creative Thinking Skills of the pupils. This is because, in Cooperative Learning Strategy peers teach one another and when someone does offer an explanation; they act as if they believe that they have something comparable to bring to the shared context. When that happens, they find the situation pleasurable (Crook, 1999) (3).And with these ingredients the social and intellectual start to work together-relationships and meanings starts to grow. If learners are involved in a task that really demands cooperation, they'll have to bridge multiple perspectives on the problem, and create a 
common ground through language. Under these conditions, their discourse becomes more thoughtful and conceptual than does that of individuals working alone (Schwartz, 1995) (4).

\section{References}

[1]. Goodlad, J. I. (1984). A place called school: Prospects for the future. New York: McGraw-Hill.

[2]. National Curriculum Framework 2005-A Study Guide.

[3]. Crook, C. (1999). Computers and the Collaborative Experience of Learning. Routledge, London, UK.

[4]. Schwartz, D. L. (1995). “ The emergence of abstract representations in dyad problem solving”. The Journal of the Learning Sciences, 4, 321-354. 